\title{
Humoral immune depression following autologous stem cell transplantation is a marker of prolonged response duration in patients with mantle cell lymphoma
}

\author{
Louise Bouard, ${ }^{1}$ Benoit Tessoulin, ${ }^{2}$ Catherine Thieblemont, ${ }^{3}$ Kamal Bouabdallah, ${ }^{4}$ Thomas \\ Gastinne, ${ }^{1}$ Lucie Oberic, ${ }^{5}$ Sylvain Carras, ${ }^{6}$ Caroline Delette, ${ }^{7}$ Olivier Casasnovas, ${ }^{8}$ Caroline \\ Dartigeas, ${ }^{9}$ Victoria Cacheux, ${ }^{10}$ Sibylle Masse, ${ }^{11}$ Olivier Hermine ${ }^{12}$ and Steven Le Gouill ${ }^{2,13}$ \\ 1Department of Hematology, CHU Nantes, Nantes; ${ }^{2}$ Department of Hematology CHU Nantes, \\ INSERM CRCINA Nantes-Angers, and NeXT, Nantes University, Nantes; ${ }^{3}$ Department of \\ Hematology, Saint-Louis Hospital, AP-HP, Paris 7 University, Paris; ${ }^{4}$ Department of \\ Hematology, CHU Bordeaux, Bordeaux; ${ }^{5}$ Department of Hematology, IUC Toulouse Oncopole, \\ Toulouse; ${ }^{6}$ Department of Hematology, CHU Grenoble, Grenoble; ${ }^{7}$ Department of \\ Hematology, CHU Amiens, Amiens; ${ }^{8}$ Department of Hematology, CHU Dijon Bourgogne, \\ INSERM 1231, Dijon; ' Department of Hematology, CHU Tours, Tours; ${ }^{10}$ Department of \\ Hematology, CHU Clermont-Ferrand, Clermont-Ferrand; "'Lysarc Institut Carnot CALYM, \\ Lyon-Sud Hospital, Lyon; ${ }^{12}$ Necker University Hospital, Paris and ${ }^{13}$ Institut Curie, Paris \\ France.
}

Correspondence: S. Le Gouill steven.legouill@curie.fr

Received: July 8, 2021.

Accepted: $\quad$ February 10, 2022.

Prepublished: February 17, 2022.

https://doi.org/10.3324/haematol.2021.279561

(อ2022 Ferrata Storti Foundation Published under a CC BY-NC license (C) $(1) \Theta$

\begin{abstract}
Rituximab maintenance (RM) after autologous stem cell transplantation (ASCT) is standard-of-care for young patients with mantle cell lymphoma (MCL). RM may enhance post-transplantation immune depression and risk of infections. We compared infection incidence and immune consequences of RM versus observation in transplanted MCL patients. All randomized patients included in the LyMa trial were eligible. The following parameters were collected prospectively: occurrence of fever, infection, hospitalization, neutropenia, hypogammaglobulinemia, CD4 lymphopenia and $\gamma$ globulin (Ig) substitution. The post-ASCT period was divided into four periods in order to assess the possible effects of RM or ASCT on immune status. Each arm included 120 patients. Concerning infection incidence and all biological parameters, there was no difference between the two arms during the first year post ASCT. After this period, RM patients were more exposed to fever $(P=0.03)$, infections $(P=0.001)$, hypogammaglobulinemia $(P=0.0001)$ and Ig substitution $(P<0.0001)$. Incidences of hospitalization, neutropenia and CD4 lymphopenia were not different between the two arms. The number of rituximab injections was correlated with infections and hypogammaglobulinemia, $P<0.0001$ and $P=0.001$; but was not correlated with neutropenia and CD4 lymphopenia. Ig substitution did not modify infection incidence. Patients who presented hypogammaglobulinemia $<6 \mathrm{~g} / \mathrm{L}$ or $<4 \mathrm{~g} / \mathrm{L}$ had longer 3 -years progression-free survival (PFS), this applies to RM patients ( $P=0.012$ and $P=0.03$ ) and to the global cohort $(P=0.008$ and $P=0.003)$. Hypogammaglobulinemia did not influence overall survival. Occurrence of infectious event, neutropenia and CD4 lymphopenia did neither influence PFS nor overall survival. Post-ASCT RM in MCL patients causes sustained hypogammaglobulinemia, which is independently correlated with improved PFS.
\end{abstract}

\section{Introduction}

Mantle cell lymphoma (MCL) is a B-cell non-Hodgkin lymphoma (NHL) which accounts for approximately $6 \%$ of NHL among adults. 'Standard-of-care for young and fit patients consists in induction with high-dose cytarabine plus rituximab containing chemotherapy, followed by autologous stem cell transplantation (ASCT). ${ }^{2}$ It has been demonstrated that a 3-year rituximab maintenance (RM) with one injection every 2 months following ASCT im- proved event-free, progression-free and overall survivals (EFS, PFS and OS respectively) ${ }^{3}$.

Rituximab is a chimeric IgG1 monoclonal antibody targeting CD20, with high efficiency in patients with B-cell lymphomas. ${ }^{4}$ Data on infectious toxicity caused by RM in $\mathrm{MCL}$ are sparse, and sometimes collected from heterogeneous or retrospective cohorts which contain different types of B-cell disorders, chemotherapy associations and treatment schedules. ${ }^{5}$ For patients with follicular lymphoma receiving $\mathrm{RM}$, prospective studies reported an increased 
infection incidence, ${ }^{6,7,8}$ but no additional infection-related deaths. ${ }^{9}$ It has been shown that prolonged rituximab administration induces hypogammaglobulinemia, ${ }^{10}$ while some authors have also reported rituximab-induced neutropenia episodes. ${ }^{11,12,13}$ Rituximab, when combined with chemotherapy, was also associated with increased incidence of opportunistic infections such as Pneumocystis jiroveci pneumonia ${ }^{14}$ and progressive multifocal leukoencephalopathy due to $J C$ virus. ${ }^{15}$ The common condition for these infections might be T CD4 lymphopenia and absence of prophylaxis for Pneumocystis infections.

$\mathrm{RM}$ is the cornerstone of MCL treatment, but there is limited reporting on its infectious and immune consequences on a homogeneous population undergoing a myeloablative procedure. Therefore, we conducted a preplanned ancillary study including patients from the LyMa trial, a phase III prospective trial in which patients were randomized between RM and observation. The primary objective was to investigate infectious and immune consequences of RM after ASCT. Secondary objectives were to describe infection sites reported, use of $\gamma$ globulin substitution as well as to analyze the impact of RM-induced immunodeficiency on patients' outcome.

\section{Methods}

\section{Patient selection}

All patients included, transplanted and randomized in the LyMa trial (clinicaltrials gov. Identifier: NCT 00921414) were considered eligible $(n=240)$. All patients provided informed consent in writing. The trial's final results have been published. In brief, 299 patients were included in LyMa trial. Two hundred and seventy-nine patients completed all four courses of R-DHAP (rituximab, dexamethasone, cytarabine and platinum derivative) induction, among whom 20 received four additional courses of RCHOP (rituximab, cyclophosphamide, doxorubicin, vincristine and prednisolone) because of an insufficient response to R-DHAP. Only those patients considered as in response, i.e., complete response (certain or uncertain) or partial response with a minimum of $75 \%$ decrease in tumor burden, were eligible for ASCT. Two hundred and fifty-seven patients received intensification with R-BEAM (rituximab, carmustine, etoposide, cytarabine and melphalan). A total of 240 were randomized between observation arm (Obs arm) and rituximab arm (RM arm). Each treatment arm included 120 patients. There was no difference in patients' characteristics, and EFS, PFS and OS were statistically better in the RM arm. ${ }^{3}$ Patients in the RM arm were planned to receive an injection of rituximab every 2 months for 3 years, for a total of 18 injections.

This study is a preplanned ancillary study of the randomized phase III trial LyMa (clinicaltrials gov. Identifier: NCT
00921414), which was approved by a formally constituted Ethics Review Board.

\section{Monitoring and end points}

Clinical examination was performed by local investigators every 2 months, before rituximab injection or during medical consultation. The following data collected prospectively were analyzed: occurrence of febrile event (defined as body temperature above $38^{\circ} \mathrm{C}$ ), occurrence of clinically documented infection (possibly non-exclusive with febrile event), hospitalization for infectious reason and Ig substitution. Occurrences of neutropenia $<0.5 \times 10^{\%} / \mathrm{L}$, T CD4 lymphopenia $<0.2 \times 10^{\%} / \mathrm{L}$ and hypogammaglobulinemia $<6 \mathrm{~g} / \mathrm{L}$ and $<4 \mathrm{~g} / \mathrm{L}$ were measured at points in time as defined by the protocol: neutrophils counts and Ig rates were collected every 2 months from month (M) 2 to M36. CD4 lymphocytes rates were measured at M2, M4, M8, M12, M24 and M36. In order to evaluate the respective impacts of ASCT and RM on infectious risk and/or impaired immune restoration, followup periods were prospectively divided into four: from randomization to 6 months (period 1), from 6 to 12 months (period 2), from 12 to 24 months (period 3 ) and from 24 months to 36 months (period 4). The division was preplanned before analysis.

\section{Statistical analysis}

The number of patients with clinical or biological events in the two arms were compared with a chi-square test or Fischer test if numbers were inferior to five. These tests are bilateral with a significance threshold of $5 \%$. For each period, the number of patients affected was compared to the number of patients not excluded from the trial (Online Supplementary Table S2). Survival data were analyzed according to the occurrence of the five following events: infectious episode, neutropenia $<0.5 \times 10^{9} / \mathrm{L}$, hypogammaglobulinemia $<6 \mathrm{~g} / \mathrm{L}$ and $<4 \mathrm{~g} / \mathrm{L}$ and CD4 lymphopenia $<0.2 \times 10^{9} / \mathrm{L}$. A Kaplan Meier survival analysis and log-rank test were conducted. Patients were set as "yes" for the occurrence of an event if it had occurred at least once at the time of analysis. Treatment-effect was estimated by hazard ratio and the confidence interval were obtained by Cox regression model. Correlation analysis and substitution by $\gamma$ globulins were compared by using the Wilcoxon test for paired data. In order to identify patients with an increased infectious risk and/or delayed immune restoration, we conducted univariate and multivariate analysis of the following variables (defined as occurrence of biological event: PNN $<0.5 \times 10^{\%} / \mathrm{L}$; Ig levels $<6 \mathrm{~g} / \mathrm{L}$ or $4 \mathrm{~g} / \mathrm{L}$ and T CD4 lymphopenia $<0.2 \times 10^{\%} / \mathrm{L}$ ). We selected epidemiologic and disease diagnostic characteristics such as sex, age, performance status, Ann Arbor stage, mantle cell lymphoma international prognostic index (MIPI) score, morphologic variant or bone marrow involvement. Morphologic, meta- 
bolic and bone marrow responses, as well as the use of salvage therapy, were also taken into account to analyze patients' response to induction. Delay between ASCT and first rituximab injection was selected to report post-ASCT hematopoietic restoration. We also analyzed the impact of the number of CD34 stem cells injected. We analyzed the number of rituximab injections in order to determine its dose effect involvement in infectious risk.

For univariate analysis, variables were compared with a Fischer test. Multivariate analysis is based on logistic regression, and includes data from the univariate analysis with a $P$-value $<0.20$.

\section{Results}

Patient characteristics, occurrence of clinical events and infections sites

The Obs and RM arms included 120 patients each. Patient characteristics and distribution are reported in the Online Supplementary Appendix. No significant difference was observed between the two arms as previously published. Concerning febrile events, the difference between the two arms was only statistically significant after 1 year post ASCT (periods 3 and 4, Table 1), with 1 of 107 patients $(0,9 \%)$ in the Obs arm versus seven of 99 patients $(7,1 \%)$ in the RM arm; and two of 89 patients $(2,3 \%)$ in the Obs arm versus ten of 97 patients (10,3\%) in the RM arm, $P=0.03$ and $P=0.02$; respectively. Median duration of fever episode was not different between the two arms: 1 day (range, 1-3) in the Obs arm versus 2 days (range, 1-15) in the RM arm, $P=0.20$. Concerning infectious events, there were significantly more infections reported in the RM arm during period 3: 28 of 99 patients (28.3\%) experienced an infection versus 11 of 107 patients (10.3\%) in the Obs arm, $P=0.001$ (Table 1). More than $50 \%$ of infectious episodes were located in the upper or lower respiratory tracts, regardless of the arm treatment or period. In the RM arm, infections sites revealing a significantly increased incidence were: upper and lower respiratory tracts; respectively $P=0.0025$ and $P=0.008$, digestive infections; $P=0.0003$ and bacteriemia; $P=0.04$; Figure 1. It should be noted that there were four and five acute pneumonia in the Obs and RM arms, respectively. In the RM arm, 13 episodes of bacterial diarrheas were reported: six Clostridium dificile colitis, five Campylobacter jejuni documentations, one Salmonella enterica documentation and one Escherichia coli documentation. The digestive tract was the only infection site with a larger proportion of total infectious episodes in the RM arm, compared to the Obs arm, $14.2 \%$ versus $3.8 \%$ respectively, $P=0.05$. Other infection sites showing similar incidences and proportions in both arms, are reported in Figure 1. Of note, there was no infections due to Pneumocystis jiroveci or LEMP due to $J C$ virus in any arm.

In total 55 hospitalizations due to infections were reported, involving 45 of 239 patients (18.8\%, Table 1). There were no differences between the two arms in any period, $P=0.61, P=1.0, P=0.09$ and $P=0.10$ for periods 1,2 , 3 and 4 , respectively. Median hospitalization duration was not different: 6 days (range, 1-25) in the Obs arm versus 6 days (range, 1-27) in RM arm, $P=0.78$.

There was no death related to infectious complications.

\section{Immune restoration and biologic parameters}

The data available for each parameter is reported in the Online Supplementary Table S2.

Table 1. Number of patients concerned by febrile events, infectious events hospitalizations due to infections and $\gamma$ globulin substitution in the two arms according to post autograft.

\begin{tabular}{|c|c|c|c|c|c|c|c|c|c|c|c|c|}
\hline & \multicolumn{3}{|c|}{$<6$ months } & \multicolumn{3}{|c|}{ 6-12 months } & \multicolumn{3}{|c|}{ 12-24 months } & \multicolumn{3}{|c|}{ 24-36 months } \\
\hline & $\begin{array}{c}\text { Obs } \\
N=120\end{array}$ & $\begin{array}{c}\text { RM } \\
N=119\end{array}$ & $\boldsymbol{P}$ & $\begin{array}{c}\text { Obs } \\
N=116\end{array}$ & $\begin{array}{c}\text { RM } \\
N=104\end{array}$ & $\boldsymbol{P}$ & $\begin{array}{c}\text { Obs } \\
N=107\end{array}$ & $\begin{array}{c}\text { RM } \\
\mathrm{N}=99\end{array}$ & $\boldsymbol{P}$ & $\begin{array}{c}\text { Obs } \\
N=89\end{array}$ & $\begin{array}{c}\text { RM } \\
\mathrm{N}=97\end{array}$ & $\boldsymbol{P}$ \\
\hline $\begin{array}{l}\text { Fever episodes } \\
\text { N patients (\%) } \\
\text { N events }\end{array}$ & $\begin{array}{c}7(5,8) \\
7\end{array}$ & $\begin{array}{c}10(8,4) \\
11\end{array}$ & 0,440 & $\begin{array}{c}1(0,9) \\
1\end{array}$ & $\begin{array}{c}5(4,8) \\
5\end{array}$ & 0,103 & $\begin{array}{c}1(0,9) \\
1\end{array}$ & $\begin{array}{c}7(7,1) \\
8\end{array}$ & 0,030 & $\begin{array}{c}2(2,2) \\
3\end{array}$ & $\begin{array}{c}10(10,3) \\
14\end{array}$ & 0,025 \\
\hline $\begin{array}{l}\text { Infectious episodes } \\
\mathrm{N} \text { patients (\%) } \\
\mathrm{N} \text { events }\end{array}$ & $\begin{array}{c}11(9,2) \\
12\end{array}$ & $\begin{array}{c}16(13,4) \\
19\end{array}$ & 0,296 & $\begin{array}{c}9(7,8) \\
11\end{array}$ & $\begin{array}{c}16(15,4) \\
22\end{array}$ & 0,075 & $\begin{array}{c}11(10,3) \\
15\end{array}$ & $\begin{array}{c}28(28,3) \\
45\end{array}$ & 0,001 & $\begin{array}{c}13(14,6) \\
13\end{array}$ & $\begin{array}{c}22(22,7) \\
41\end{array}$ & 0,159 \\
\hline $\begin{array}{l}\text { Hospitalizations } \\
\text { N patients (\%) } \\
\text { N events }\end{array}$ & $\begin{array}{c}8(6,7) \\
8\end{array}$ & $\begin{array}{c}10(8,4) \\
11\end{array}$ & 0,611 & $\begin{array}{c}5(4,3) \\
5\end{array}$ & $\begin{array}{c}4(3,8) \\
5\end{array}$ & 1,000 & $\begin{array}{c}3(2,8) \\
3\end{array}$ & $\begin{array}{c}8(8,1) \\
9\end{array}$ & 0,092 & $\begin{array}{c}3(3,4) \\
4\end{array}$ & $\begin{array}{c}9(9,3) \\
10\end{array}$ & 0,101 \\
\hline $\begin{array}{l}\gamma \text { globulin } \\
\text { substitution } \\
\mathrm{N} \text { patients (\%) } \\
\mathrm{N} \text { events }\end{array}$ & $\begin{array}{c}2(2) \\
9\end{array}$ & $\begin{array}{c}6(6,2) \\
19\end{array}$ & 0,171 & $\begin{array}{c}2(2) \\
10\end{array}$ & $\begin{array}{c}5(5,2) \\
41\end{array}$ & 0,259 & $\begin{array}{c}5(5) \\
23\end{array}$ & $\begin{array}{c}11(11,3) \\
48\end{array}$ & 0,0075 & $\begin{array}{c}1(1) \\
3\end{array}$ & $\begin{array}{c}19(19,6) \\
165\end{array}$ & $<.0001$ \\
\hline
\end{tabular}

Obs: observation arm; RM: rituximab maintenance arm. 


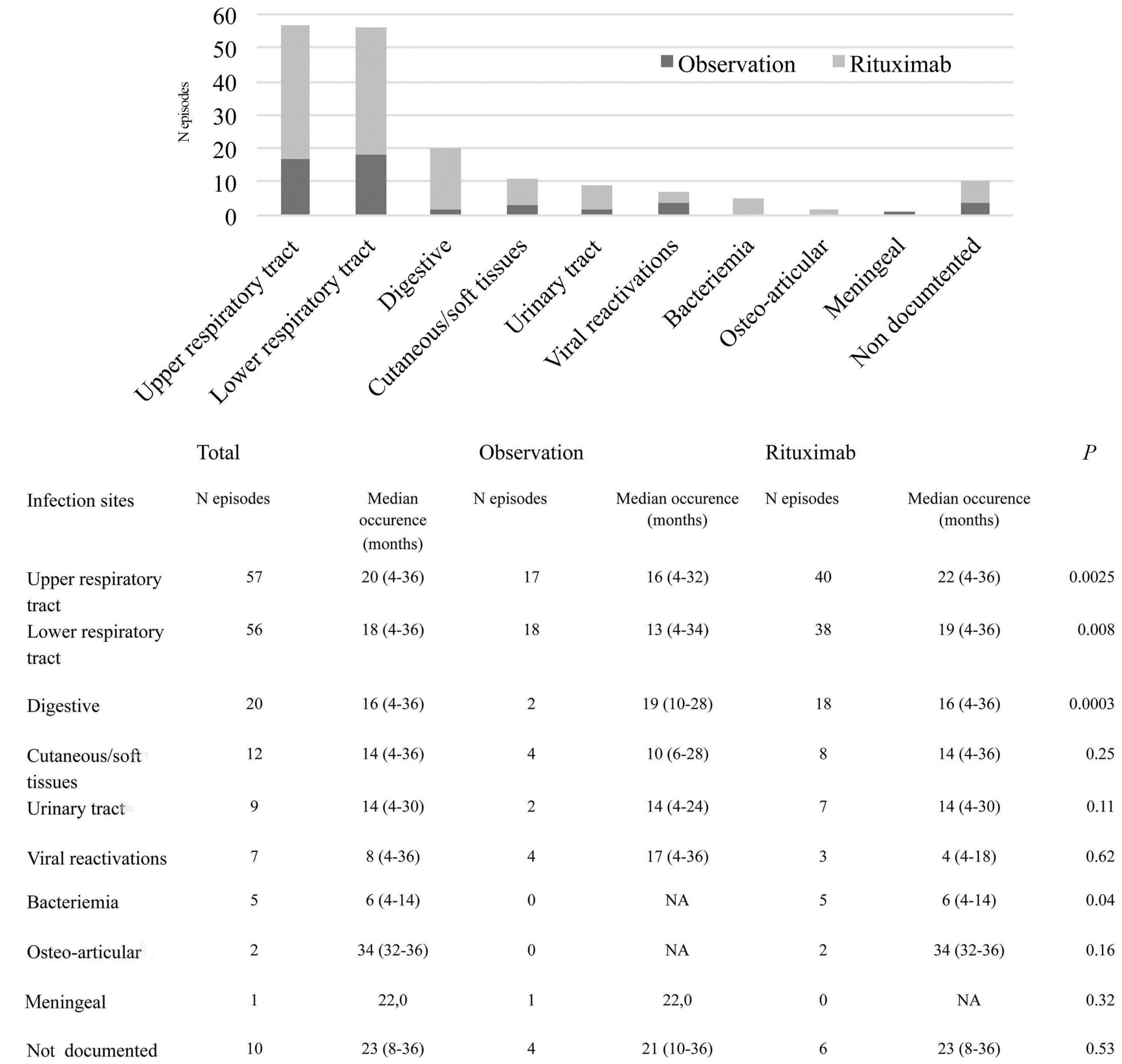

Figure 1. Infection sites. (A) Graphical repartition of infections sites. (B) Number of infections per infection sites presented with median time of occurrence.

\section{Neutropenia}

Concerning neutropenia $<0,5 \times 10^{\%} / \mathrm{L}$, there was no difference between the two arms for any period, $P=0.26, P=0.10$, $P=0.61$ and $P=\mathrm{NA}$, respectively, in chronological order (Table 2). For all patients, the median time of occurrence of neutropenia was located in period 1: 2.40 months (range, 0-30.8 months). However, the median time of occurrence was significantly delayed in the RM arm: 4.35 months (range, 0.6-19.8 months) versus 1.86 months (range, 0.0-16.1 months) in the Obs arm, $P=0.048$.

\section{$Y$ globulin levels}

Using a $6 \mathrm{~g} / \mathrm{L}$ cutoff, the difference between the two groups with regards to hypogammaglobulinemia was statistically significant only after 1 year post ASCT, $P<0.0001$ (Table 2). During period 3, 56 of 107 patients $(52.3 \%)$ in the Obs arm versus 77 of 99 patients $(77.8 \%)$ in
RM arm presented at least one event of hypogammaglobulinemia, $P<0.0001$. During period 4, 38 of 89 patients $(42.7 \%)$ in the Obs arm versus 82 of 97 patients (84.5\%) in the RM arm presented at least one event of hypogammaglobulinemia, $P<0.0001$. Using a $4 \mathrm{~g} / \mathrm{L}$ cutoff, the difference was statistically significant as from 6 months post ASCT. During period 2, 20 of 116 patients (17.2\%) presented hypogammaglobulinemia in the Obs arm versus 34 of 104 patients $(32.7 \%)$ in the RM arm, $P=0.0078$. During period 3 , 16 of 107 patients (15.0\%) presented events of hypogammaglobulinemia in the Obs arm versus 38 of 99 patients (38.4\%) in the RM arm, $P=0.0001$. During period 4,15 of 89 patients $(16.9 \%)$ presented events of hypogammaglobulinemia in the Obs arm versus 46 of 97 patients (47.4\%) and 114 events in the RM arm, $P<0.0001$. In the Obs and RM arms, Ig median rate changed from $5.11 \mathrm{~g} / \mathrm{L}$ (range, 2.111.1) to $6.41 \mathrm{~g} / \mathrm{L}$ (range, 0.6-11.7) and from $4.68 \mathrm{~g} / \mathrm{L}$ (range, 
Table 2. Number of patients concerned by neutropenia, hypogammaglobulinemia and T CD4 lymphopenia in the two arms according to post autograft periods.

\begin{tabular}{|c|c|c|c|c|c|c|c|c|c|c|c|c|}
\hline & \multicolumn{3}{|c|}{$<6$ months } & \multicolumn{3}{|c|}{ 6-12 months } & \multicolumn{3}{|c|}{ 12-24 months } & \multicolumn{3}{|c|}{ 24-36 month } \\
\hline & $\begin{array}{c}\text { Obs } \\
N=120\end{array}$ & $\begin{array}{c}\text { RM } \\
\text { N=119 }\end{array}$ & $\boldsymbol{P}$ & $\begin{array}{c}\text { Obs } \\
N=116\end{array}$ & $\begin{array}{c}\text { RM } \\
N=104\end{array}$ & $\boldsymbol{P}$ & $\begin{array}{c}\text { Obs } \\
N=107\end{array}$ & $\begin{array}{c}\text { RM } \\
\mathrm{N}=99\end{array}$ & $\boldsymbol{P}$ & $\begin{array}{c}\text { Obs } \\
N=89\end{array}$ & $\begin{array}{c}\text { RM } \\
\mathbf{N}=97\end{array}$ & $\boldsymbol{P}$ \\
\hline $\begin{array}{l}\text { Neutropenia }<0,5 \times 10^{9} / \mathrm{L} \\
\mathrm{N} \text { patients }(\%) \\
\mathrm{N} \text { events }\end{array}$ & $\begin{array}{c}13(10,8) \\
15\end{array}$ & $\begin{array}{c}8(6,7) \\
8\end{array}$ & 0,26 & $\begin{array}{c}0(0) \\
0\end{array}$ & $\begin{array}{c}3(2,9) \\
4\end{array}$ & 0,10 & $\begin{array}{c}1(0,9) \\
1\end{array}$ & $\begin{array}{c}2(2,0) \\
2\end{array}$ & 0,61 & $\begin{array}{c}0(0) \\
0\end{array}$ & $\begin{array}{c}0(0) \\
0\end{array}$ & NA \\
\hline $\begin{array}{l}\text { Hypogamma } \\
\text { globulinemia }<6 \mathrm{~g} / \mathrm{L} \\
\mathrm{N} \text { patients }(\%) \\
\mathrm{N} \text { events } \\
\text { Hypogamma } \\
\text { globulinemia }<4 \mathrm{~g} / \mathrm{L} \\
\mathrm{N} \text { patients }(\%) \\
\mathrm{N} \text { events }\end{array}$ & $\begin{array}{c}80(66,7) \\
163 \\
\\
30(25,0) \\
57\end{array}$ & $\begin{array}{c}85(71,4) \\
154 \\
\\
38(31,9) \\
56\end{array}$ & 0,24 & $\begin{array}{c}67(57,8) \\
131 \\
\\
20(17,2) \\
39\end{array}$ & $\begin{array}{c}63(60,6) \\
127 \\
\\
34(32,7) \\
53\end{array}$ & 0,67 & $\begin{array}{c}56(52,3) \\
169 \\
\\
16(15,0) \\
35\end{array}$ & $\begin{array}{c}77(77,8) \\
243 \\
\\
38(38,4) \\
104\end{array}$ & 0,0001 & $\begin{array}{c}38(42,7) \\
126 \\
\\
15(16,9) \\
38\end{array}$ & $\begin{array}{c}82(84,5) \\
266 \\
\\
46(47,4) \\
114\end{array}$ & $<0,001$ \\
\hline $\begin{array}{l}\text { T CD4 lymphopenia } \\
<0,2 \times 10^{9} / \mathrm{L} \\
\mathrm{N} \text { patients (\%) } \\
\mathrm{N} \text { events }\end{array}$ & $\begin{array}{c}17(14,2) \\
18\end{array}$ & $\begin{array}{c}19(16,0) \\
20\end{array}$ & 0,70 & $\begin{array}{c}14(12,1) \\
17\end{array}$ & $\begin{array}{c}11(10,6) \\
14\end{array}$ & 0,73 & $\begin{array}{c}0(0) \\
0\end{array}$ & $\begin{array}{c}2(2) \\
2\end{array}$ & 0,23 & $\begin{array}{c}1(1,1) \\
1\end{array}$ & $\begin{array}{c}1(1,0) \\
1\end{array}$ & 1,00 \\
\hline
\end{tabular}

Obs: observation arm; RM: rituximab maintenance arm.

$1.6-10.3$ ) to $4.68 \mathrm{~g} / \mathrm{L}$ (range, 1.0-9.5), from period 1 to period 4, respectively. Median rates of Ig significantly differed between the two arms in periods 3 and $4: 6.11 \mathrm{~g} / \mathrm{L}$ (range, 1.2-12.9) versus $4.70 \mathrm{~g} / \mathrm{L}$ (range, 1.2-9.1), $P<0.0001$ and $6.41 \mathrm{~g} / \mathrm{L}$ (range, 0.6-11.7) versus 4.68 (range, 1.0-9.5), $P<0.0001$, for the Obs and RM arms, respectively.

\section{T CD4 lymphopenia}

Concerning T CD4 lymphopenia, there was no difference between the two arms for any of the periods, $P=0.70$, $P=0.73, P=0.23$ and $P=1.0$, in chronological order respectively (Table 2). In the Obs arm, median rates of T CD4 lymphocytes increased from $0.320 \times 10 \% / L$ (range, 0.0-0.980) to $0.670 \times 10^{9} / \mathrm{L}$ (range, $0.100-1.312$ ) in periods 1 to 4 . These values were respectively $0.300 \times 10^{9} / \mathrm{L}$ (range, 0.0-1.021) and $0.630 \times 10^{9} / \mathrm{L}$ (range, 0.200-0.885) the in RM arm. Median rate did not differ between the two arms during any of the periods: $P=0.83, P=0.44, P=0.08$ and $P=0.45$, in chronological order respectively.

Biological events are reported in Figure 2.

\section{Y globulin substitution}

In the Obs arm, five of 120 patients (4.2\%) received 45 substitutions, while in the RM arm, 23 of 119 patients (19.3\%) received 273 substitutions, $P=0.0002$. In period 4 , one patient of $89(1.1 \%)$ received three substitutions in the Obs arm while 19 of 97 (19.6\%) received 165 substitutions in the RM arm, $P<0.0001$, Table 1. For those patients substituted, median number of substitutions was 8 (range, 119) in the Obs arm versus 6 (range, 1-82) in the RM arm, which was not different, $P=0.93$. Correlation analysis showed that Ig substitution was correlated with hypogammaglobulinemia $<6 \mathrm{~g} / \mathrm{L}$ and $<4 \mathrm{~g} / \mathrm{L}(P=0.035$ and
$P<0.001$, respectively) and occurrence of infectious episodes $(P=0.002)$. As of the first substitutive injection, the number of hypogammaglobulinemia $<6 \mathrm{~g} / \mathrm{L}$ and $<4 \mathrm{~g} / \mathrm{L}$ events was significantly reduced, the median difference (before-after) being 3.5 events, $P=0.037$. However, the median number of infectious episodes within patient (before-after) was not reduced with Ig substitution, even after a dozen of injections, $P=0.09$.

\section{Impact of immune restoration and occurrence of infectious events on progression-free survival and overall survival}

Occurrence of infectious events did not impact PFS or OS in either arm (Obs arm, PFS $P=0.31$ and OS $P=0.55$; RM arm PFS $P=0.13$ and OS $P=0.09$ ) nor did it impact $P F S$ or $O S$ in the whole cohort (PFS $P=0.08$ and OS $P=0.16$ ). This was also noted for the occurrence of neutropenia (Obs arm, PFS $P=0.16$ and OS $P=0.26$; RM arm PFS $P=0.96$ and $O S$ $P=0.21$; whole cohort PFS, $P=0.28$ and OS $P=0.10$ ). In contrast, occurrence of hypogammaglobulinemia $<6 \mathrm{~g} / \mathrm{L}$ $(\mathrm{n}=86 / 120 ; 71.6 \%$ in the Obs arm and $n=103 / 119,86.3 \%$ in the RM arm, $n=189 / 239 ; 79.1 \%$ in the whole cohort) was correlated with an improved 36 months PFS in the whole cohort $(85.6 \%$ vs. $63.6 \%, P=0.0005$; Figure $3 \mathrm{~A})$, with a treatment arm adjusted hazard ratio $(H R)=0.488(95 \% \mathrm{Cl}$ : 0.287-0.830; $P=0.008)$. In the RM arm, 36 months PFS was also improved in patients with hypogammaglobulinemia (93.2\% vs. 63.5\%, $P=0.008$; Figure 3B, $\mathrm{HR}=0.294$; $95 \% \mathrm{Cl}$ : 0.113-0.767). In the Obs arm, this was not significant, $P=0.09$. For a hypogammaglobulinemia cutoff at $4 \mathrm{~g} / \mathrm{L}$ $(n=40 / 120,33.3 \%$ in the Obs arm; $n=71 / 119,59.7 \%$ in $R M$ arm and $n=111 / 239,46.4 \%$ in the whole cohort), PFS also correlated with occurrence of hypogammaglobulinemia, 

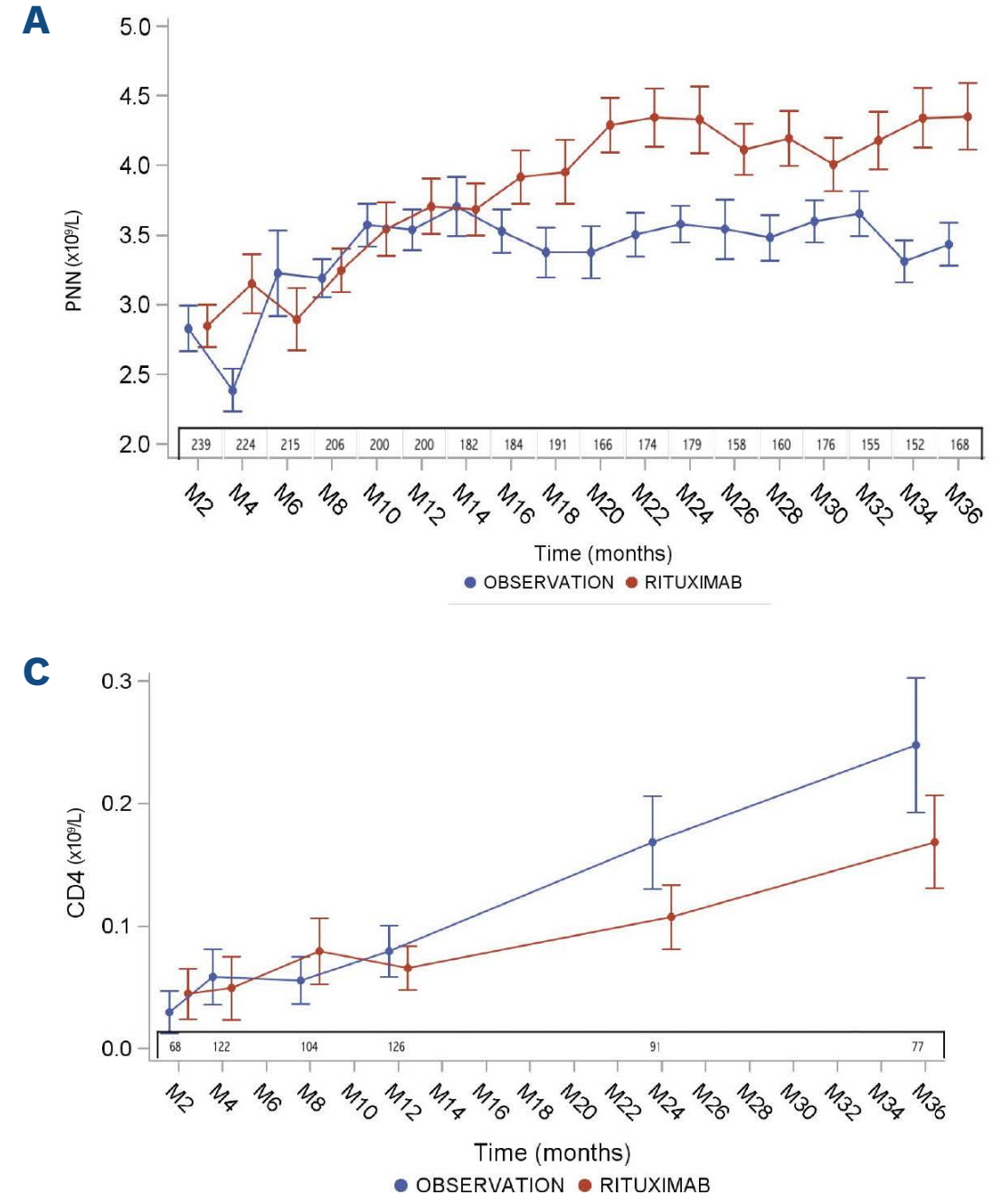

with a 36 months PFS of $90 \%$ versus $73.2 \%, P=0.003$ in the whole cohort (HR adjusted on treatment arm $=0.562,95 \%$ $\mathrm{Cl}$ : 0.324-0.975, $P=0.003$; Figure $3 \mathrm{C}$ ) and a 36 months PFS of $95.7 \%$ versus $79.5 \%, P=0.03$ in the $R M$ arm ( $H R=0.384$; 95\% Cl: 0.157-0.941; Figure 3D). In the Obs arm, this was not significant, $P=0.36$. When adjusted on number of rituximab injections, impact of hypogammaglobulinemia on PFS was still significant, with a $\mathrm{HR}=0,565 ; 95 \% \mathrm{Cl}$ : 0,3340,$955 ; P=0,033$. There was no impact of hypogammaglobulinemia $(<6 \mathrm{~g} / \mathrm{L}$ or $<4 \mathrm{~g} / \mathrm{L})$ on $O S$ in the whole cohort $(P=0.45$ and $P=0.48$ ) or in any arm (Obs arm, $P=0.75$ and $P=0.38$; RM arm, $P=0.22$ and $P=0.22$ ). Occurrence of CD4 lymphopenia did not impact PFS or OS in the whole cohort (PFS, $P=0.10$ and OS $P=0.95$ ) nor did it impact $P F S$ or OS in either arm (Obs arm : PFS, $P=0.16$ and OS $P=0.98$; RM arm : PFS, $P=0.38$ and OS $P=0.98$ ).

\section{Statistical analyses regarding risk of infections and delayed immune restoration}

Univariate analysis

Univariate analysis demonstrated that performance status 0 at diagnosis was associated with lower risk of CD4 lymphopenia, $P=0.02$. Receiving more than half of the maintenance program (nine rituximab injections) was associated with an increased risk of infectious episode, $P<0.001$ as well as hypogammaglobulinemia < $6 \mathrm{~g} / \mathrm{L}, P=0.02$ and $<4 \mathrm{~g} / \mathrm{L}, P=0.03$. Neutropenia was not associated with any variable. Univariate analysis is reported in Table 3.

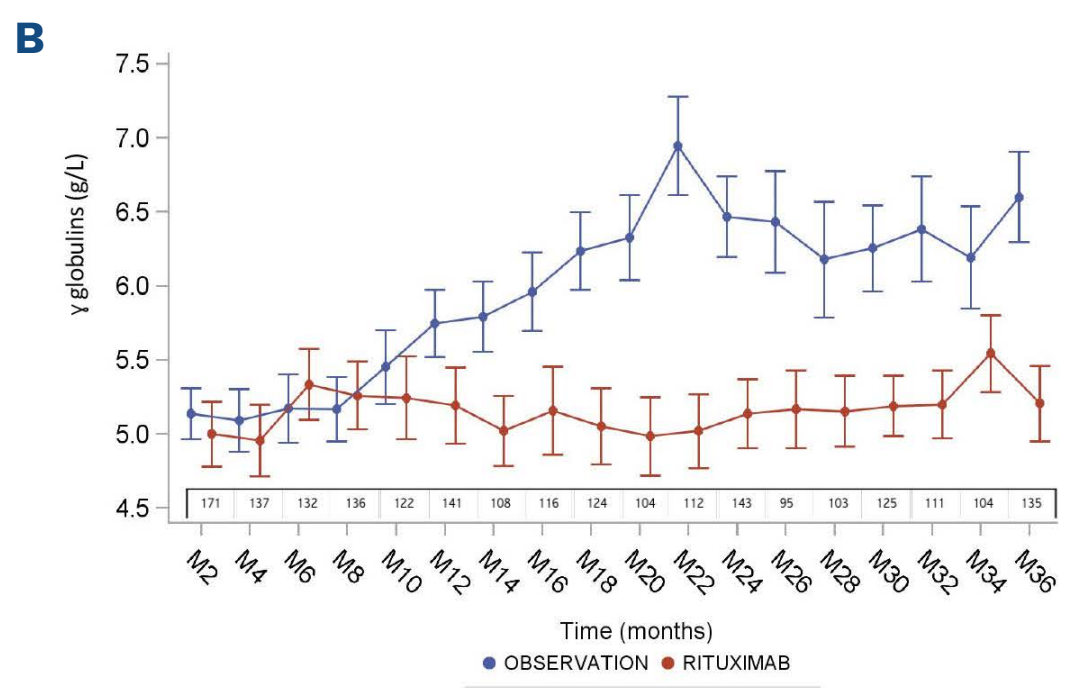

Figure 2. Rates of polynuclear neutrophils, $\gamma$ globulins and CD4 lymphocytes according to treatment arms. (A) Polynuclear neutrophils (PNN), (B) $\gamma$ globulins and (C) CD4 lymphocytes.

\section{Multivariate analysis}

In multivariate analysis, patients presenting with a classic morphologic variant at diagnosis had less risk of hypogammaglobulinemia $<6 \mathrm{~g} / \mathrm{L}$ (odds ratio $[\mathrm{OR}]=0.278,95 \% \mathrm{Cl}$ : 0.086-0.899, $P=0.033$ ). Performance status 0 at diagnosis appeared to be a protective factor for occurrence of CD4 lymphopenia (OR=0.423, 95\% Cl: 0.220-0.812, $P=0.01$ ). Complete response after induction increased the risk factor of hypogammaglobulinemia $<6 \mathrm{~g} / \mathrm{L},(\mathrm{OR}=2.972,95 \% \mathrm{Cl}$ : 1.263-6.994, $P=0.013)$. Patients who received more than nine rituximab injections had more infectious episodes; (OR=11.17, 95\% Cl: 2.482-50.263, $P=0.002)$ and increased occurrence of hypogammaglobulinemia $<6 \mathrm{~g} / \mathrm{L}$; (OR=4.278, 95\% Cl: 1.393-13.141, $P=0.01)$ and $<4 \mathrm{~g} / \mathrm{L},(\mathrm{OR}=2.882,95 \%$ Cl:1.131-73.45, $P=0.03)$. No risk or protective factor was identified for neutropenia occurrence. Multivariate analysis is represented in Table 4.

\section{Discussion}

Our study shows that RM after ASCT increases infectious risk but only as from 12 months post ASCT. This suggests that during the first year post ASCT, infectious risk is related to the ASCT conditioning regimen and not to RM. The most reported infection sites were upper and lower respiratory tracts with a significantly higher proportion of bacterial colitis episodes in RM. Among the biological parameters tested, only 1-year post-ASCT hypogamma- 
A

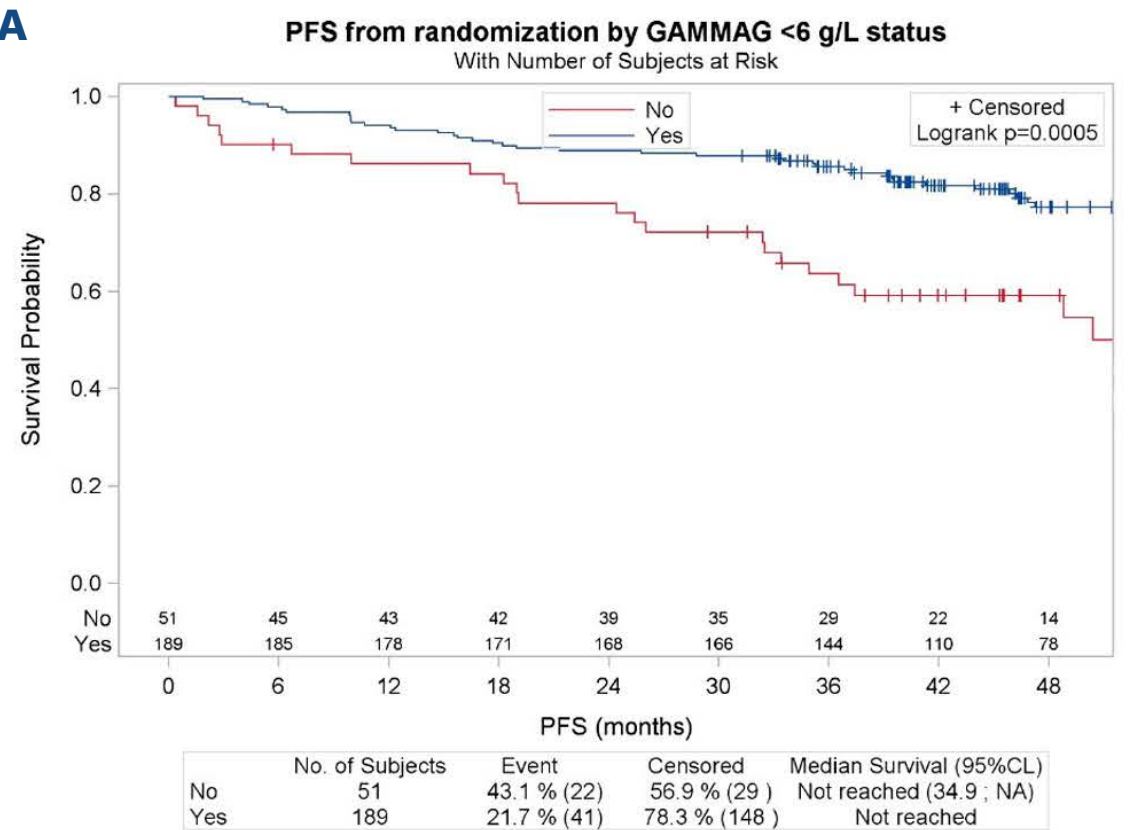

C

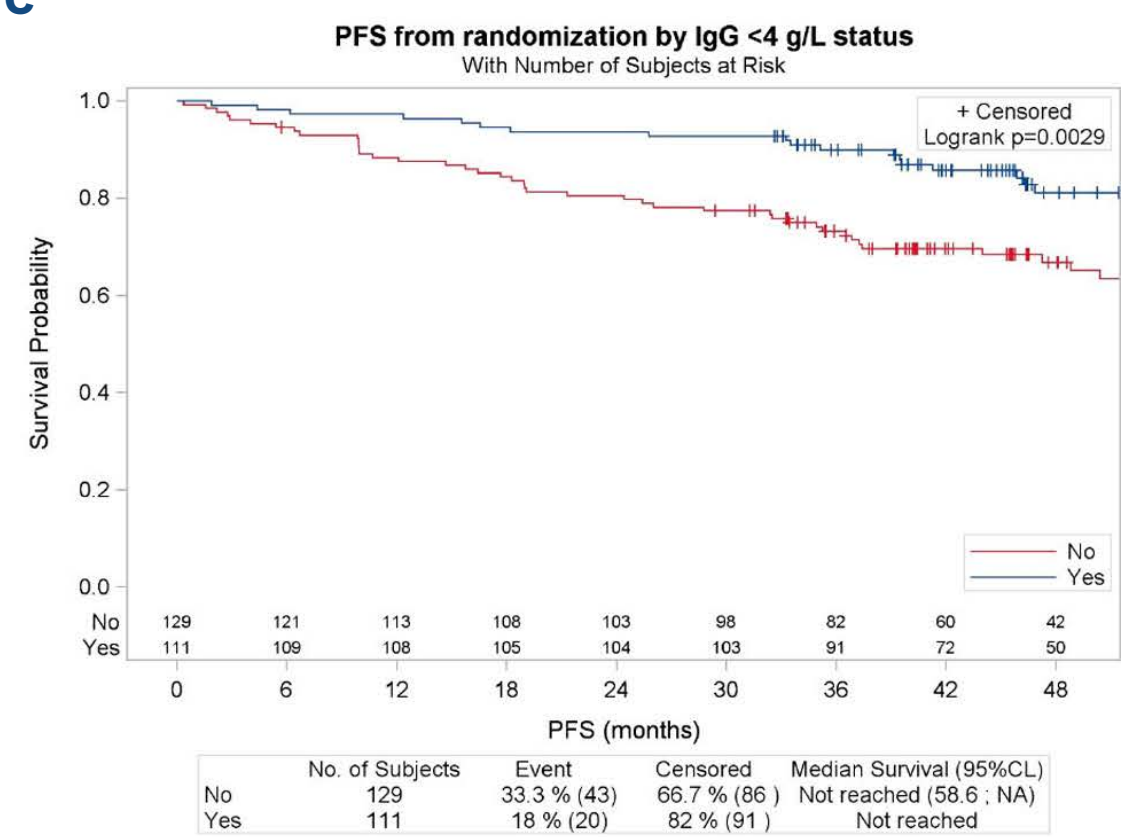

B PFS from randomization by GAMMAG $<6 \mathrm{~g} / \mathrm{L}$ status (RITUXIMAB)

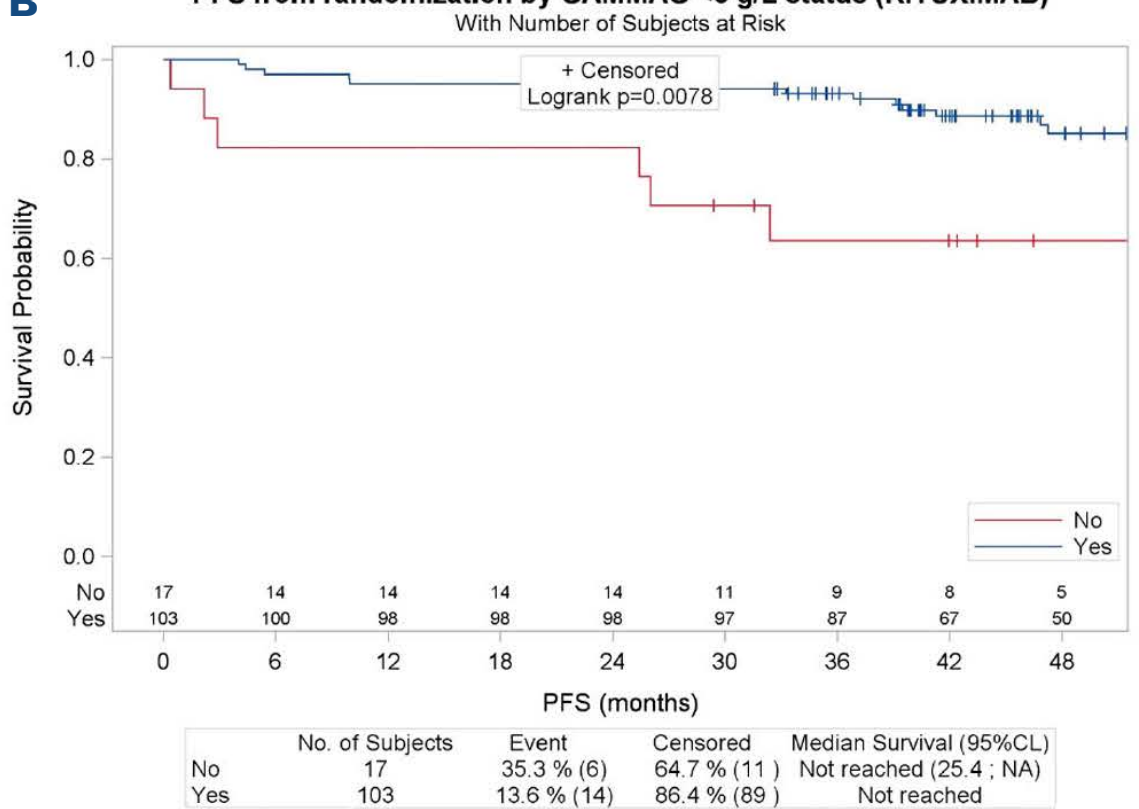

D

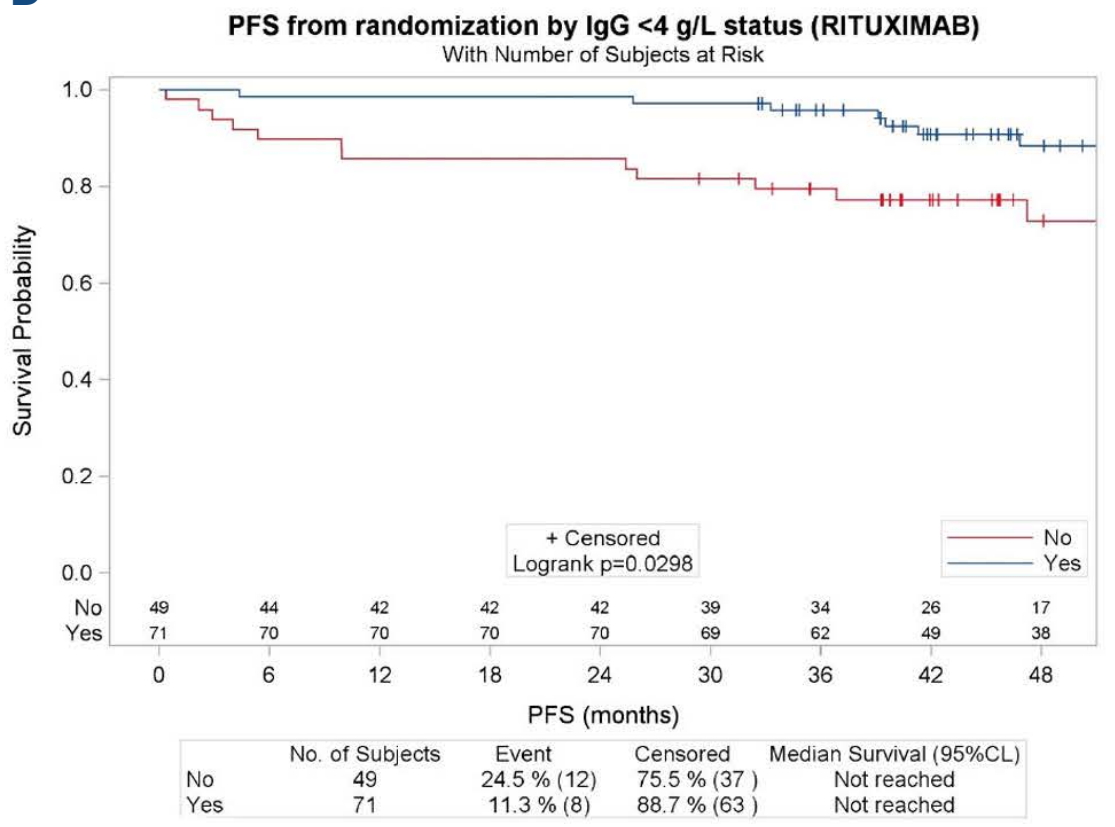

Figure 3. Progression-free survival from randomization according to occurrence of hypogammaglobulinemia <6 g/L and hypogammaglobulinemia $<\mathbf{4} \mathbf{g} / \mathbf{L}$. Representation of progression-free survival (PFS) in (A) the whole cohort and in (B) the rituximab maintenance (RM) arm according to $\gamma$ globulin status $<6 \mathrm{~g} / \mathrm{L}$ and PFS in (C) the whole cohort and in (D) the RM arm according to occurrence of hypogammaglobulinemia <4 g/L. GAMMAG: $\gamma$ globulin rate.

globulinemia was statistically more frequent in RM. This highlights the side effect of RM on humoral immunity. Multivariate analysis shows that patients who received at least nine rituximab injections, which amounts to half the maintenance program, are more exposed to infectious events and hypogammaglobulinemia. Our work corroborates previously reported findings on the cumulative effect of RM on infectious risk. ${ }^{10}$

Although data were collected and monitored prospectively, our study has its limits: microbiological documentations are frequently missing mainly because the vast majority of infections were of low grade in upper and lower respiratory tracts which are not routinely explored by physicians in practice. In addition, the LyMa trial electronic case report form (e-CRF) did not report treatment prophylaxis and use of granulocyte colony-stimulating factor (G-CSF) support but we can presume that, according to international guidelines ${ }^{16}$ in this post-ASCT setting, the patients did receive at least P.jiroveci and herpes simplex virus prophylaxis and probably G-CSF support when needed. Thus, we can not conclude about these associated measures and treatments. Unfortunately, LyMa e-CRF did not report the vaccination strategy used for patients and thus patients were vaccinated according to local vaccination strategy in each center. We believe that European Society for Blood and Marrow Transplantation recommendations ${ }^{17}$ were applied. We also did not investigate the impact of recurring low grade infection consequences on quality of life. However, the higher incidence of infections in the RM arm is offset by its benefits in terms of EFS, PFS and OS. This higher incidence could be explained, to a large extent, by the occurrence of hypogammaglobulinemia after 1 year post transplant, and not by neutropenia or T CD 4 depletion. Ig substitution was not recommended in the LyMa trial and was left to the choice of investigator in 
Table 3. Univariate analysis for infectious episode, neutropenia, hypogammaglobulinemia and CD4 lymphopenia.

\begin{tabular}{|c|c|c|c|c|c|c|c|c|}
\hline \multirow[b]{2}{*}{$\begin{array}{l}\text { Sex } \\
\text { Male } \mathrm{N}=189 \\
\text { Female } \mathrm{N}=51\end{array}$} & \multicolumn{2}{|c|}{$\begin{array}{c}\text { Infectious episode } \\
\text { (\%) }\end{array}$} & \multicolumn{2}{|c|}{$\begin{array}{c}\text { Neutropenia } \\
(\%)\end{array}$} & \multicolumn{2}{|c|}{$\begin{array}{l}\text { Hypogamma- } \\
\text { globulinemia } \\
<6 \times 10 \% \text { L(\%) }\end{array}$} & \multicolumn{2}{|c|}{$\begin{array}{c}\text { CD4 lymphopenia } \\
(\%)\end{array}$} \\
\hline & $\begin{array}{l}32.3 \\
41.2\end{array}$ & 0.25 & $\begin{array}{c}11.1 \\
9.8\end{array}$ & 1.0 & $\begin{array}{l}78.8 \\
82.4\end{array}$ & 0.70 & $\begin{array}{l}21.2 \\
17.6\end{array}$ & 0.70 \\
\hline $\begin{array}{l}\text { Age } \\
\qquad 60 \text { y } N=172 \\
>60 \text { y } N=68\end{array}$ & $\begin{array}{l}34.9 \\
32.4\end{array}$ & 0.76 & $\begin{array}{c}8.7 \\
16.2\end{array}$ & 0.11 & $\begin{array}{l}78.5 \\
82.4\end{array}$ & 0.60 & $\begin{array}{l}22.7 \\
14.7\end{array}$ & 0.21 \\
\hline $\begin{array}{l}\text { PS } \\
\begin{array}{l}0 \mathrm{~N}=156 \\
1 \mathrm{~N}=74 \\
2 \mathrm{~N}=10\end{array}\end{array}$ & $\begin{array}{l}35.9 \\
33.8 \\
10.0\end{array}$ & 0.27 & $\begin{array}{c}9.6 \\
13.5 \\
10.0\end{array}$ & 0.60 & $\begin{array}{l}81.4 \\
77.0 \\
70.0\end{array}$ & 0.47 & $\begin{array}{l}16.0 \\
31.1 \\
10.0\end{array}$ & 0.02 \\
\hline $\begin{array}{l}\text { Ann arbor } \\
\text { II } N=12 \\
\text { III } N=31 \\
\text { IV N=196 }\end{array}$ & $\begin{array}{l}50.0 \\
25.8 \\
34.2\end{array}$ & 0.30 & $\begin{array}{c}8.3 \\
9.7 \\
11.2\end{array}$ & 1.0 & $\begin{array}{r}100 \\
77.4 \\
78.6\end{array}$ & 0.22 & $\begin{array}{c}8.3 \\
25.8 \\
20.4\end{array}$ & 0.49 \\
\hline $\begin{array}{l}\text { MIPI score } \\
\text { Low } \mathrm{N}=133 \\
\text { Int } \mathrm{N}=65 \\
\text { High } \mathrm{N}=42\end{array}$ & $\begin{array}{l}33.8 \\
41.5 \\
23.8\end{array}$ & 0.17 & $\begin{array}{c}9.8 \\
12.3 \\
11.9\end{array}$ & 0.81 & $\begin{array}{l}80.5 \\
73.8 \\
85.7\end{array}$ & 0.33 & $\begin{array}{l}21.1 \\
18.5 \\
21.4\end{array}$ & 0.91 \\
\hline $\begin{array}{l}\text { Morphologic variant } \\
\text { Classic } \mathrm{N}=134 \\
\text { Others } \mathrm{N}=36\end{array}$ & $\begin{array}{l}31.3 \\
33.3\end{array}$ & 0.84 & $\begin{array}{c}8.2 \\
13.9\end{array}$ & 0.34 & $\begin{array}{l}76.1 \\
88.9\end{array}$ & 0.11 & $\begin{array}{l}20.1 \\
25.0\end{array}$ & 0.50 \\
\hline $\begin{array}{l}\text { Bone marrow involvement } \\
\text { Yes } N=149 \\
\text { No } N=72\end{array}$ & $\begin{array}{l}36.2 \\
27.8\end{array}$ & 0.46 & $\begin{array}{c}12.8 \\
6.9\end{array}$ & 0.44 & $\begin{array}{l}79.9 \\
79.2\end{array}$ & 0.90 & $\begin{array}{l}20.8 \\
19.4\end{array}$ & 0.87 \\
\hline $\begin{array}{l}\text { PS post R-DHAC } \\
\text { O N=163 } \\
1 \mathrm{~N}=67 \\
2 \mathrm{~N}=4\end{array}$ & $\begin{array}{l}32.5 \\
34.3 \\
25.0\end{array}$ & 0.95 & $\begin{array}{l}14.1 \\
4.5 \\
0.0\end{array}$ & 0.11 & $\begin{array}{r}78.5 \\
80.6 \\
100\end{array}$ & 0.83 & $\begin{array}{l}19.6 \\
23.9 \\
25.0\end{array}$ & 0.63 \\
\hline $\begin{array}{l}\text { PET post R-DHAC } \\
\text { Pos. } \mathrm{N}=51 \\
\text { Neg. } \mathrm{N}=175\end{array}$ & $\begin{array}{l}37.3 \\
35.4\end{array}$ & 0.87 & $\begin{array}{c}9.8 \\
11.4\end{array}$ & 1.0 & $\begin{array}{l}80.4 \\
78.9\end{array}$ & 1.0 & $\begin{array}{l}23.5 \\
18.9\end{array}$ & 0.55 \\
\hline $\begin{array}{l}\text { Medullar response post R-DHAC } \\
\text { Yes } N=179 \\
\text { No } N=5\end{array}$ & $\begin{array}{c}33.0 \\
0.0\end{array}$ & 0.18 & $\begin{array}{l}10.1 \\
20.0\end{array}$ & 0.42 & $\begin{array}{c}78.8 \\
100\end{array}$ & 0.59 & $\begin{array}{c}21.2 \\
0.0\end{array}$ & 0.59 \\
\hline $\begin{array}{l}\text { CT scanner post R-DHAC } \\
\text { Cr N=115 } \\
\operatorname{Pr}>75 \% \mathrm{~N}=97 \\
\operatorname{Pr}<75 \% \mathrm{~N}=22\end{array}$ & $\begin{array}{l}33.0 \\
33.0 \\
45.5\end{array}$ & 0.51 & $\begin{array}{l}10.4 \\
11.3 \\
9.1\end{array}$ & 0.95 & $\begin{array}{l}83.5 \\
73.2 \\
90.0\end{array}$ & 0.07 & $\begin{array}{l}18.3 \\
22.7 \\
27.3\end{array}$ & 0.52 \\
\hline $\begin{array}{l}\text { RCHOP salvage } \\
\text { Yes } N=11 \\
\text { No } N=229\end{array}$ & $\begin{array}{l}36.4 \\
34.1\end{array}$ & 1.0 & $\begin{array}{l}18.2 \\
10.5\end{array}$ & 0.34 & $\begin{array}{l}100 \\
78.6\end{array}$ & 0.13 & $\begin{array}{l}18.2 \\
20.5\end{array}$ & 1.0 \\
\hline $\begin{array}{l}\text { Asct-maintenance delay } \\
\quad<=2 \text { mth } N=91 \\
>2 \text { mth } N=149\end{array}$ & $\begin{array}{l}38.5 \\
31.5\end{array}$ & 0.33 & $\begin{array}{l}12.1 \\
10.1\end{array}$ & 0.67 & $\begin{array}{l}82.4 \\
77.9\end{array}$ & 0.42 & $\begin{array}{l}23.1 \\
18.8\end{array}$ & 0.51 \\
\hline $\begin{array}{l}\text { Number of } \mathrm{CD} 34 / \mathrm{kg} \\
\quad<5.106 \mathrm{~N}=73 \\
5-8.106 \mathrm{~N}=76 \\
>8.106 \mathrm{~N}=90\end{array}$ & $\begin{array}{l}35.6 \\
26.3 \\
40.0\end{array}$ & 0.17 & $\begin{array}{c}8.2 \\
14.5 \\
8.9\end{array}$ & 0.42 & $\begin{array}{l}78.1 \\
84.2 \\
76.7\end{array}$ & 0.45 & $\begin{array}{l}17.8 \\
21.1 \\
21.1\end{array}$ & 0.86 \\
\hline $\begin{array}{l}\text { Number of RM injections (in RM group only) } \\
<=9 \text { inj } N=23 \\
>9 \text { inj } N=97\end{array}$ & $\begin{array}{c}8.7 \\
51.5\end{array}$ & $<.001$ & $\begin{array}{l}11.9 \\
9.3\end{array}$ & 0.67 & $\begin{array}{l}69.6 \\
90.7\end{array}$ & 0.014 & $\begin{array}{l}19.6 \\
21.6\end{array}$ & 0.75 \\
\hline
\end{tabular}

PS: performance status; PET: positron emission tomography; CT: computerized tomography; inj: injections; R-DHAC: rituximab, dexamethasone, cytarabine and platinum derivative; RCHOP: rituximab, cyclophosphamide, doxorubicin, vincristine and prednisolone; RM: rituximab maintenance; ASCT: autologous stem cell transplantation; MIPI: mantle cell lymphoma international prognostic index; mth: months. 
Table 4. Multivariate analysis for infectious episode, neutropenia, hypogammaglobulinemia and CD4 lymphopenia.

\begin{tabular}{|l|c|c|c|}
\hline & Modality & OR & 95\% CI \\
\hline Infectous episode & $>9$ ritux inj & 11.17 & $2.482-50.263$ \\
\hline Neutropenia & - & - & - \\
\hline & & $\mathbf{0 . 0 0 1 7}$ & - \\
\hline Hypogammaglobulinemia $<6 \times 10^{9} / \mathrm{L}$ & Classical morphologic variant & 0.278 & $0.086-0.899$ \\
\hline Hypogammaglobulinemia $<4 \times 10^{9} / \mathrm{L}$ & Morphologic CR & 2.972 & $1.263-6.994$ \\
\hline CD4 lymphopenia & $>9$ ritux inj & 4.278 & $\mathbf{0 . 0 3 3}$ \\
\hline
\end{tabular}

Inj: injection; CR: complete response; PS: performance status; int: interval; OR: odds ratio; Cl: confidence interval; ritux: rituximab.

each center. Lack of efficacy of the Ig substitution might suggest that other factors could also be involved or that Ig substitution fails to restore an active humoral immunity. Therefore, our study questions the relevance of Ig substitution which has an added financial cost. In the absence of a prospective randomized study, our study does not call for a systematic use of Ig substitution, including for patients with recurrent infections. Another interesting finding of our work is the relationship between hypogammaglobulinemia and complete response, as well as prolonged duration of response. Although there is a guaranteed time bias as hypogammaglobulinemia can develop only late post transplant, very few patients presented an hypogammaglobulinemia after having recovered an Ig level superior of $6 \mathrm{~g} / \mathrm{L}$ and the relationship between hypogammaglobulinemia and PFS was still significant when adjusted on the number of rituximab injections. Moreover, we conducted a landmark methodology (every 2 months from M2 to M36) which did not highlight the appropriate and precise time point for monitoring Ig level. This might suggest that rituximab-induced $\mathrm{B}$-cell depletion indirectly reflect the rituximab anti-MCL effect. This hypothesis is supported by the multivariate analysis showing a dose effect relationship between rituximab and hypogammaglobulinemia. However, improved PFS for hypogammaglobulinemic patients does nor only reflect a rituximab dose effect, as it is still significant when adjusted on number of rituximab injections. Other parameters such as FCGR3A gene polymorphism could also explain discrep- ancies between patients in terms of rituximab anti-MCL effect.18,19

In conclusion, our work highlights the B-cell and humoral immunodepression induced by RM as from 1-year post transplant in MCL patients. Prior to 1 year, humoral immune status reflects effects of rituximab before the transplant and the transplant procedure itself. RM does neither induce a higher incidence of neutropenia nor T CD4 depletion which are the result of the transplant procedure. Ig substitution remains an open question although it doesn't appear to balance the hypogammaglobulinemia-induced infections. Interestingly, hypogammaglobulinemia could become a surrogate marker for the RM anti-MCL effect.

\section{Disclosures \\ No conflicts of interest to disclose.}

\section{Contributions}

$\angle B$ and $S L G$ performed the research and wrote the manuscript; BT and SB analyzed the data. All other authors gave advice and supervised the writing of the manuscript.

\section{Funding}

This work is an ancillary study of The LyMa trial which was funded by Roche SAS.

\section{Data-sharing statement}

Data of the present work will be shared upon request to the corresponding author.

\section{References}

1. Jain P, Wang M. Mantle cell lymphoma: 2019 update on the diagnosis, pathogenesis, prognostication, and management. Am J Hematol. 2019;94(6):710-725.

2. Dreyling $M$, Campo E, Hermine $O$, et al. Newly diagnosed and relapsed mantle cell lymphoma: ESMO Clinical Practice
Guidelines for diagnosis, treatment and follow-up. Ann Oncol. 2017;28(Suppl 4):S62-71.

3. Le Gouill S, Thieblemont C, Oberic L, et al. Rituximab after autologous stem-cell transplantation in mantle-cell lymphoma. N Engl J Med. 2017;377(13):1250-1260. 
4. Coiffier B. Treatment of non-Hodgkin's lymphoma: a look over the past pecade. Clin Lymphoma Myeloma.

2006;7 (Suppl 1):S7-13.

5. Forstpointner R, Unterhalt M, Dreyling M, et al. Maintenance therapy with rituximab leads to a significant prolongation of response duration after salvage therapy with a combination of rituximab, fludarabine, cyclophosphamide, and mitoxantrone ( $\mathrm{R}-\mathrm{FCM}$ ) in patients with recurring and refractory follicular and mantle cell lymphomas: results of a prospective randomized study of the German Low Grade Lymphoma Study Group (GLSG). Blood. 2006;108(13):4003-4008.

6. van Oers MHJ, Van Glabbeke M, Giurgea L, et al. Rituximab maintenance treatment of relapsed/resistant follicular nonHodgkin's lymphoma: long-term outcome of the EORTC 20981 phase III randomized Intergroup Study. J Clin Oncol. 2010;28(17):2853-2858.

7. Vidal L, Gafter-Gvili A, Salles G, et al. Rituximab maintenance improves overall survival of patients with follicular lymphomaIndividual patient data meta-analysis. Eur J Cancer. 2017;76:216-225.

8. Salles G, Seymour JF, Offner F, et al. Rituximab maintenance for 2 years in patients with high tumour burden follicular lymphoma responding to rituximab plus chemotherapy (PRIMA): a phase 3 , randomised controlled trial. Lancet. 2011;377(9759):42-51.

9. Pettengell R, Uddin R, Boumendil A, et al. Durable benefit of rituximab maintenance post-autograft in patients with relapsed follicular lymphoma: 12-year follow-up of the EBMT lymphoma working party Lym1 trial. Bone Marrow Transplant. 2021;56(6):1413-1421.

10. Casulo C, Maragulia J, Zelenetz AD. Incidence of hypogammaglobulinemia in patients receiving rituximab and the use of intravenous immunoglobulin for recurrent infections. Clin Lymphoma Myeloma Leuk. 2013;13(2):106-111.
11. Stamatopoulos K, Papadaki T, Pontikoglou C, et al. Lymphocyte subpopulation imbalances, bone marrow hematopoiesis and histopathology in rituximab-treated lymphoma patients with late-onset neutropenia. Leukemia. 2008;22(7):1446-1449.

12. Dunleavy K. B-cell recovery following rituximab-based therapy is associated with perturbations in stromal derived factor-1 and granulocyte homeostasis. Blood. 2005;106(3):795-802.

13. Aksoy S, Dizdar Ö, Hayran M, Harputluoglo H. Infectious complications of rituximab in patients with lymphoma during maintenance therapy: a systematic review and meta-analysis. Leuk Lymphoma. 2009;50(3):357-365.

14. Jiang $X$, Mei X, Feng D, Wang X, Tanowitz H. Prophylaxis and treatment of pneumocystis jiroveci pneumonia in lymphoma patients subjected to rituximab-contained therapy: a systemic review and meta-analysis. Tanowitz HB, éditeur. PLoS One. 2015;10(4):e0122171.

15. Carson KR, Evens AM, Richey EA, et al. Progressive multifocal leukoencephalopathy after rituximab therapy in HIV-negative patients: a report of 57 cases from the Research on Adverse Drug Events and Reports project. Blood. 2009;113(20):4834-4840.

16. Taplitz RA, Kennedy EB, Bow EJ, et al. Antimicrobial prophylaxis for adult patients with cancer-related immunosuppression: ASCO and IDSA clinical practice guideline update. J Clin Oncol. 2018;36(30):3043-3054.

17. Ljungman $\mathrm{P}$, Cordonnier $\mathrm{C}$, Einsele $\mathrm{H}$, et al. Vaccination of hematopoietic cell transplant recipients. Bone Marrow Transplant. 2009;44(8):521-526.

18. Cartron G, Dacheux L, Salles G, et al. Therapeutic activity of humanized anti-CD20 monoclonal antibody and polymorphism in IgG Fc receptor FcyRIIla gene. Blood. 2002;99(3):754-758.

19. Kim DH, Jung HD, Kim JG, et al. FCGR3A gene polymorphisms may correlate with response to frontline R-CHOP therapy for diffuse large B-cell lymphoma. Blood. 2006;108(8):2720-2725. 